Int. J. Electrochem. Sci., 11 (2016) $4802-4811$

\title{
Square Wave Voltammetric Determination of Rasagiline Mesylate on Hanging Mercury Drop Electrode and its application in Dosage Form and Biological Fluids
}

\author{
Ibrahim H.I. Habib ${ }^{1}$, Mohamed Rizk ${ }^{2}$, Dalia Mohamed ${ }^{2,3}$, Shereen Mowaka ${ }^{2,4}$ and \\ Rasha Th. El-Eryan ${ }^{2, *}$ \\ ${ }^{1}$ Microanalytical Chemistry Laboratory, Applied Organic Chemistry Department, National Research \\ Centre, Dokki, 12622, Giza, Egypt \\ ${ }^{2}$ Analytical Chemistry Department, Faculty of Pharmacy, Helwan University, 11745, Cairo, Egypt. \\ ${ }^{3}$ Pharmaceutical Analytical Chemistry Department, Faculty of Pharmacy, October \\ University for Modern Sciences and Arts, 11787, 6 October City, Egypt \\ ${ }^{4}$ Analytical Chemistry Department, Faculty of Pharmacy, British University in Egypt, \\ 11837, El-Sherouk City, Egypt \\ *E-mail: rashaeleryan@ @otmail.com
}

doi: $10.20964 / 2016.06 .64$

Received: 16 February 2016 / Accepted: 26 March 2016 / Published: 4 May 2016

\begin{abstract}
A new square wave voltammetric (SWV) method has been developed and validated for the determination of Rasagiline mesylate in bulk, dosage form and human plasma due to a cathodic behaviour of its acetylene group at Hanging Mercury Drop Electrode (HMDE). Many facts such as different supporting electrolytes, scan rate, pulse amplitude, accumulation time and accumulation potential were studied. A good linearity was obtained over a concentration range of $\left(2.8 \times 10^{-8}\right.$ to 1.4 $\mathrm{x} 10^{-7} \mathrm{~mol} \mathrm{~L}^{-1}$ ) with $99.78 \%$ as mean recovery and $1.09 \%$, as the relative standard deviation and limits of detection and quantification were found to be $\left(2.7 \times 10^{-9}\right.$ and $\left.9.24 \times 10^{-9} \mathrm{~mol} \mathrm{~L}^{-1}\right)$, respectively. The accuracy and precision of the method were within acceptable limits. The method was applied for determining the active ingredients in its tablets with $\%$ recoveries \pm relative standard deviation of $95.46 \pm 3.76$ and in spiked human plasma with $94.3 \pm 2.89 \%$, respectively.
\end{abstract}

Keywords: Rasagiline mesylate; Square Wave Voltammetry; Hanging Mercury Drop Electrode; acetylene group.

\section{FULL TEXT}

(C) 2016 The Authors. Published by ESG (www.electrochemsci.org). This article is an open access article distributed under the terms and conditions of the Creative Commons Attribution license (http://creativecommons.org/licenses/by/4.0/). 